\title{
Two decades of data reveal that Biological Invasions needs to increase participation beyond North America, Europe, and Australasia
}

\author{
Martin A. Nuñez (D) Mariana C. Chiuffo • Hanno Seebens • Sara Kuebbing • \\ Matthew A. McCary • Deah Lieurance · Bo Zhang • Daniel Simberloff • \\ Laura A. Meyerson (1)
}

Received: 6 October 2021 / Accepted: 17 October 2021 / Published online: 17 November 2021

(C) The Author(s), under exclusive licence to Springer Nature Switzerland AG 2021

\begin{abstract}
Most published papers in ecology come from a handful of countries, and invasion science as an ecological subdiscipline is no exception. Based on the country of corresponding authors, we analyzed patterns in submissions, reviews, and publications in the journal Biological Invasions from its first issue in 1999 to 2020. Regionally, North America, Europe, and Australasia submitted and published the most articles during this period and supplied most reviewers and journal editors. As a country, the USA stands out in
\end{abstract}

\section{A. Nuñez $(\square)$}

Department of Biology and Biochemistry, University of Houston, Houston, TX 77204, USA

e-mail: nunezm@gmail.com

M. A. Nuñez $\cdot$ M. C. Chiuffo

Grupo de Ecología de Invasiones, INIBIOMA,

CONICET, Universidad Nacional del Comahue, Quintral

1250, CP 8400 San Carlos de Bariloche, Argentina

H. Seebens

Senckenberg Biodiversity and Climate Research Centre, Georg-Voigt-Straße 14-16, 60325 Frankfurt, Germany

\section{S. Kuebbing}

Department of Biological Sciences, University of Pittsburgh, Pittsburgh, PA 15260, USA

M. A. McCary

Department of BioSciences, Rice University, Houston,

TX 77005, USA terms of papers published and reviewers involved in the process. The dominance of published articles from USA-based scientists declined through time, but such articles still constitute one-third of all articles in recent years. However, as biological invasions are a worldwide phenomenon acting on local to global scales, research from all regions of the world is needed to better understand and manage invasions. By tracking and reporting the trends in the countries of origin of the journal's authors and reviewers, and by encouraging

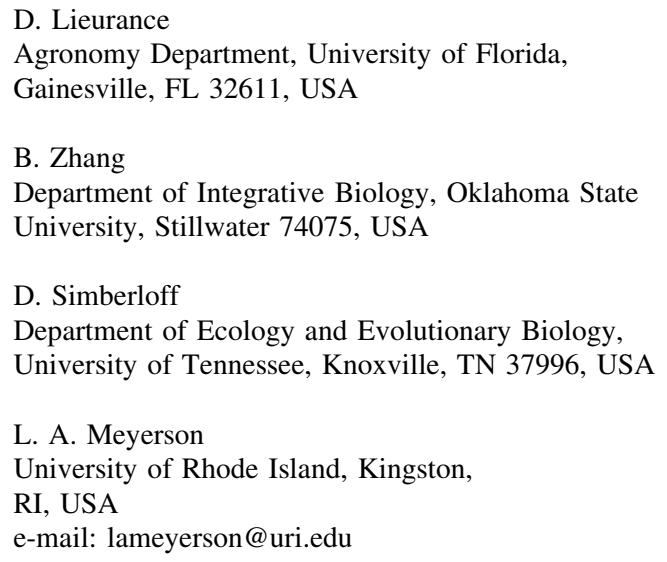


submissions from more countries, we hope that geographical differences will decrease and that a more global understanding of biological invasions will emerge.

Keywords Diversity - Bias · Inclusiveness - Global science

\section{Introduction}

Recent studies in ecology and related disciplines show that researchers from a handful of countries publish the majority of scientific articles, while publications from many regions of the world are poorly represented in international journals (Martin et al. 2012; Lowry et al. 2013; Mammides et al. 2016; Manlove and Belou 2018; Nuñez et al. 2019; Maas et al. 2021). This skewed geographic distribution of international journal publications has many causes often related to socio-economic factors (Barlow et al. 2018) but is also due to language barriers (Amano and Sutherland 2013; Amano et al. 2016). As a consequence, we lack adequate knowledge of a significant number of regions, thereby limiting our understanding of ecological problems and potential solutions. Our scientific disciplines and management approaches are further impoverished because they often do not include the perspectives and insights of researchers and managers who may view the world through different lenses.

The recent report on invasions in Antarctica (e.g., Hughes et al. 2020) made evident that no area of the planet is free from risk of invasion. Geographical disparity in the peer-reviewed literature can deeply affect our understanding of invasions. Are the tropics indeed less invaded, as has often been asserted (cf. Chong et al. 2021), or are tropical invasions simply underrepresented in the literature? What are the main drivers of invasions, and can this question be answered without a more geographically balanced global literature? Which traits facilitate plant invasions and do these vary geographically? Are there fewer invasive species in central Africa relative to central Europe? We may attempt to answer such questions, but without solid global knowledge and data, our answers are at most tentative, and in some cases, possibly wrong.

The geographical disparity in publications of leading journals is a problem not only for understanding but also for managing invasive species. For a thorough understanding of the phenomena that will help to inform management in both donor and recipient countries, we need a holistic understanding of the process. An incomplete geographic view of biological invasions can have serious consequences for how researchers understand invasions and how practitioners and policymakers address this urgent topic (Nagendra 2018). In particular, resistance or vulnerability to invasion varies by taxa, biotic and abiotic conditions of the recipient ecosystem (including extant invasions), and economic and cultural factors. Therefore, different regions may require different prevention and management approaches based on the respective invasive species, ecosystem type, available resources, and available expertise (Nuñez and Pauchard 2010). Tools for proper management and real economic costs can be missed if knowledge from some regions is neglected, particularly owing to language barriers (Nagendra 2018; Angulo et al. 2021).

Here, we analyzed the geographical distribution of corresponding authors and invited reviewers in Biological Invasions by country of institutional affiliation. One goal is to highlight the distribution of countries from which papers are being submitted and published and the pool from which reviewers are being drawn. A second goal, also shared by Kuebbing et al. (2021), which focuses on the Biological Invasions editorial board demography, is to identify potential geographic disparities in the review and publication process in order to reduce regional and country-level disparities in Biological Invasions. The main goals of this analysis are to add transparency to the publication process of the journal and to attract more submissions from countries that are poorly represented in the journal to expand global coverage and enrich invasion science overall.

\section{Methods}

Springer-Nature provided us with the following information from two databases. One database recorded corresponding authors and the other recorded reviewers. Below we explain in detail both databases. 
Author database

Querying the author database for Biological Invasions, we analyzed geographical patterns of manuscript submission (2003-2020) and articles accepted (1999-2020) in the journal Biological Invasions using the countries of the institutional affiliation of the corresponding author. We focused on corresponding authors in order to streamline and focus our analysis. While we recognize that this approach ignores international collaborations on many papers, Springer maintains a database of corresponding authors only, not all authors. Data on submissions were unavailable before 2003 because the journal was published by Kluwer prior to this time and records were not transferred when Springer became the publisher in 2003.

\section{Reviewer database}

We investigated the geographic locations of reviewer invitations and acceptances using data from all reviewer invitations and acceptances for Biological Invasions from 2003 to 2020. As for author data (above), Biological Invasions was published by Kluwer prior to 2003, after which Springer became the publisher. No records of reviewers were available prior to 2003.

\section{Analysis}

We built cartograms to illustrate geographic differences of manuscript submissions and acceptances to Biological Invasions, as well as the number of reviewers per country. The numbers of submissions, acceptances, and reviewers per country were used to distort country land areas using the 'Cartogram' package (Jeworutzki 2016). To account for population size and facilitate drawing comparisons among countries, we normalized our data and built cartograms of manuscript submissions and acceptances, and reviewers per million inhabitants. We calculated rates per million inhabitants as follows: $\frac{\text { Number of articles }}{\text { Estimated country population }} * 1000000$.

We used population size and the list of countries of the World Bank (UNESCO Institute for Statistics 2018). To analyze temporal changes, we calculated the annual total numbers of manuscripts and countries of corresponding author's affiliation for both submitted and accepted articles. Temporal changes could not be analyzed for the reviewer database owing to a lack of annual information.

\section{Results}

Manuscript submissions and acceptances

Overall, Biological Invasions has published 3478 articles since 1999. From 2003 to 2020, Biological Invasions received a total of 9838 submissions, of which 3339 were accepted, corresponding to an overall acceptance rate of $34 \%$. On a continental scale and over the 22-year period analyzed, Biological Invasions received the most manuscripts from North America $(\mathrm{n}=3208)$, followed by Europe $(\mathrm{n}=2852)$ (Fig. 1a, Table 1). The next highest numbers of submissions originated from Asia $(n=1479)$, Latin America (including the Caribbean) $(\mathrm{n}=1068)$ and Australasia $(\mathrm{n}=783)$, while the fewest came from Africa $(n=356)$ and Pacific Islands $(n=21)$. Rates of manuscript acceptance for publication were higher for submissions from North America (49\%) and Australasia (45\%), followed by Europe (34\%), while rates were around $25 \%$ for all other regions. However, when population size by country is considered, the numbers of submissions and acceptances per million inhabitants show a somewhat different pattern (Fig. 1b). In the cartograms country sizes are represented in relation to their number of submissions and acceptances. North America, particularly the USA, recedes in dominance and New Zealand and Australia gain importance owing to the high number of articles published and relatively low population sizes (Fig. 1b).

On a national scale, submissions were dominated by the USA $(n=2694)$ (Fig. 1$)$. The second-largest number of submissions, four times lower, was from China $(n=615)$ followed by Australia (560), Brazil (513), Spain (496), Canada (369), and UK (330) (Table 2). Manuscript acceptance rates were highest for New Zealand, Sweden, Switzerland, and the USA. Interestingly, ten of the twelve countries with acceptance rates of at least $40 \%$ are countries with English as a first language or Scandinavian countries known to have a high level of English proficiency among their populations. Switzerland and the Czech Republic were 
(a)
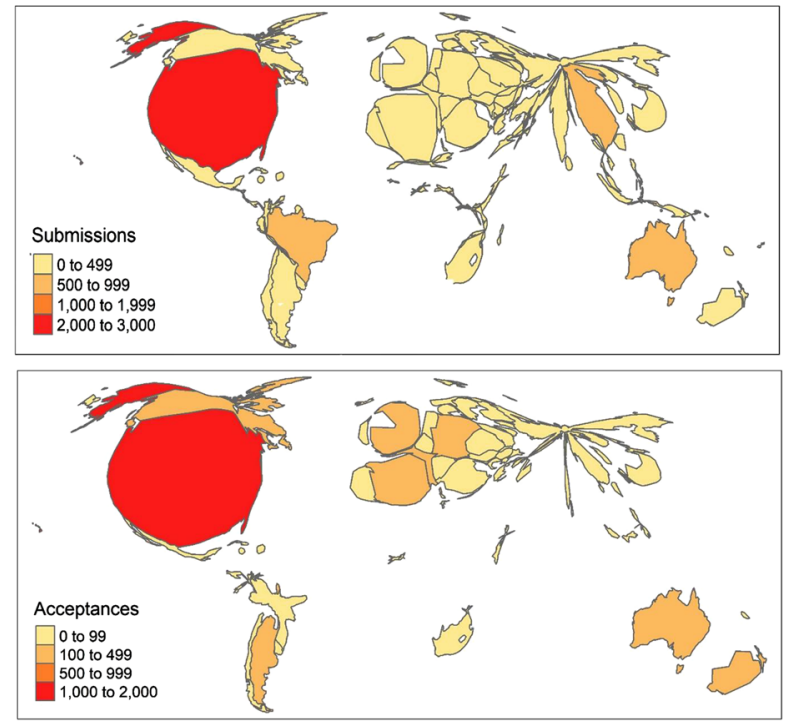

Fig. 1 a Cartograms showing distorted land area of countries based on their contributions of submissions (top panel) and acceptances (bottom panel) to the journal Biological Invasions. We used the corresponding author's country of institutional affiliation for articles received between 2003 and 2020 and (b)
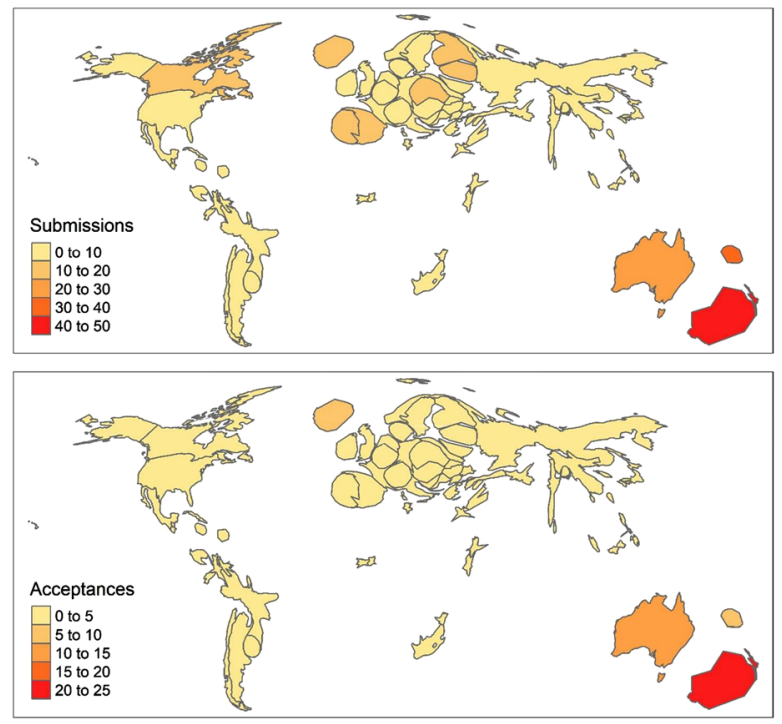

articles accepted between 1999 and 2020. b Cartograms with resized land area based on numbers of papers submitted and accepted per million inhabitants in each country to the journal Biological Invasions from 1999 to 2020

Table 1 Number of submitted articles, accepted articles, and invited and accepted reviewers from 2003 to 2020 for continental regions

\begin{tabular}{|c|c|c|c|c|c|c|}
\hline Region & $\begin{array}{l}\text { Submitted } \\
\text { articles }\end{array}$ & $\begin{array}{l}\text { Accepted } \\
\text { articles }\end{array}$ & $\begin{array}{l}\text { Acceptance } \\
\text { rates }\end{array}$ & $\begin{array}{l}\text { Invited } \\
\text { reviewers }\end{array}$ & $\begin{array}{l}\text { Accepted } \\
\text { reviewers }\end{array}$ & $\begin{array}{l}\text { Rate of } \\
\text { acceptance }\end{array}$ \\
\hline Africa & 356 & 93 & 0.26 & 718 & 389 & 0.54 \\
\hline Asia & 1479 & 232 & 0.16 & 688 & 355 & 0.52 \\
\hline Australasia & 783 & 347 & 0.44 & 2461 & 1456 & 0.59 \\
\hline Europe & 2858 & 946 & 0.33 & 6625 & 3775 & 0.57 \\
\hline North America & 3208 & 1466 & 0.46 & 13,608 & 7752 & 0.57 \\
\hline Pacific Islands & 21 & 5 & 0.24 & 0 & 0 & 0 \\
\hline South America & 1068 & 245 & 0.23 & 1176 & 629 & 0.53 \\
\hline
\end{tabular}

the other two countries with an acceptance rate of $40 \%$ or more.

Based on the institutional affiliation of the corresponding authors, the journal received submissions from 132 countries and published articles from 76 countries. Because there are 195 countries worldwide as defined in our database, this means that based on corresponding authors alone, researchers from $32 \%$ of all countries have never submitted a manuscript to the journal during this period, and researchers from $61 \%$ of countries have not published a single article in Biological Invasions. Corresponding authors from only five countries (USA, China, Australia, Spain, and Brazil) submitted $50 \%$ of the published articles, and corresponding authors from three countries (USA, Australia, and Canada) published $51 \%$ of all papers 
Table 2 Number of submitted articles, accepted articles, and invited and accepted reviewers during the period of 2003 to 2020 for the top twenty countries with the most submitted articles

\begin{tabular}{|c|c|c|c|c|c|c|}
\hline Country & $\begin{array}{l}\text { Submitted } \\
\text { articles }\end{array}$ & $\begin{array}{l}\text { Accepted } \\
\text { articles }\end{array}$ & $\begin{array}{l}\text { Acceptance } \\
\text { rates }\end{array}$ & $\begin{array}{l}\text { Invited } \\
\text { reviewers }\end{array}$ & $\begin{array}{l}\text { Accepted } \\
\text { reviewers }\end{array}$ & $\begin{array}{l}\text { Rate of } \\
\text { acceptance }\end{array}$ \\
\hline United States & 2694 & 1276 & 0.47 & 12,205 & 6884 & 0.56 \\
\hline China & 615 & 93 & 0.15 & 302 & 159 & 0.53 \\
\hline Australia & 560 & 235 & 0.42 & 1599 & 908 & 0.57 \\
\hline Brazil & 513 & 80 & 0.16 & 359 & 175 & 0.49 \\
\hline Spain & 496 & 158 & 0.32 & 743 & 372 & 0.5 \\
\hline Canada & 369 & 165 & 0.45 & 1314 & 821 & 0.62 \\
\hline $\begin{array}{l}\text { United } \\
\text { Kingdom }\end{array}$ & 330 & 133 & 0.4 & 1347 & 824 & 0.61 \\
\hline Italy & 317 & 87 & 0.27 & 491 & 284 & 0.58 \\
\hline Argentina & 310 & 104 & 0.34 & 589 & 322 & 0.55 \\
\hline Germany & 293 & 110 & 0.38 & 773 & 414 & 0.54 \\
\hline France & 275 & 101 & 0.37 & 820 & 498 & 0.61 \\
\hline India & 251 & 14 & 0.06 & 61 & 34 & 0.56 \\
\hline New Zealand & 223 & 112 & 0.5 & 862 & 548 & 0.64 \\
\hline South Africa & 219 & 77 & 0.35 & 718 & 389 & 0.54 \\
\hline Japan & 210 & 59 & 0.28 & 160 & 79 & 0.49 \\
\hline Poland & 159 & 22 & 0.14 & 113 & 66 & 0.58 \\
\hline Portugal & 154 & 50 & 0.32 & 264 & 140 & 0.53 \\
\hline Mexico & 145 & 25 & 0.17 & 89 & 47 & 0.53 \\
\hline Chile & 133 & 33 & 0.25 & 221 & 130 & 0.59 \\
\hline Czechia & 120 & 48 & 0.4 & 319 & 182 & 0.57 \\
\hline
\end{tabular}

(Fig. 1a, b). When one accounts for population size, New Zealand, American Samoa, Australia, and Switzerland become the leaders (highest number of papers published per capita). However, acceptance rates also vary widely by country and region, ranging from $49 \%$ in North America to 5\% in Pacific Islands (Tables 1, 2).

Biological Invasions received an increasing number of submissions following 2004 with a particularly steep $(265 \%)$ increase in submissions between 2006 and 2011 (Fig. 2). Likewise, the number of accepted articles rose, although at a lower rate (144\%), from 2006 to 2011. Although the number of submissions plateaued after 2011, the number of countries of first author's affiliation has increased continuously until the present. However, for accepted manuscripts, the number of countries remained rather constant since 2011 at around 34 countries of corresponding author's affiliation on average. The proportion of papers submitted from the USA seems to be fairly constant over time while acceptances show a decline, especially from 1999 to 2009 .

\section{Manuscript reviews}

By far, most invitations were sent to reviewers from North America (Fig. 3, Table 1), while European researchers received only half as many, and still fewer were sent to reviewers from other regions. The rate of acceptances of reviewer invitations was surprisingly constant around 50-60\% across all regions. In line with submissions, by far most reviewers were invited from the United States (47\% of all invited reviewers), while for Australia, United Kingdom, and Canada rates were $6-7 \%$, and for other countries the number of invited reviewers was below $5 \%$. When one accounts for population size, New Zealand, American Samoa, and Australia had the highest number of reviewer invitations $(17 \%, 10 \%$ and $6 \%$ of all invited reviewers normalized by population sizes, respectively). 

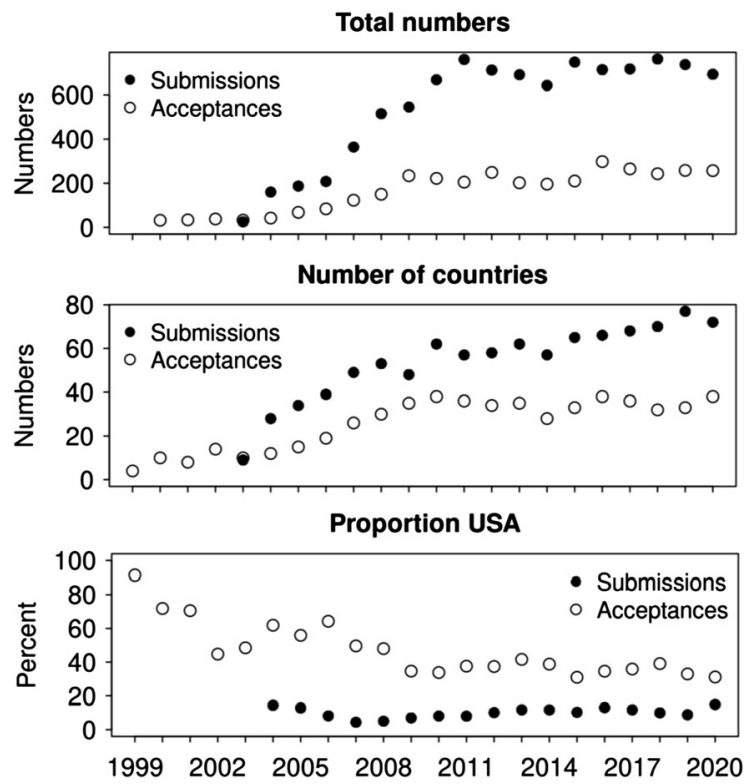

Fig. 2 Time series of total numbers of articles, numbers of countries, and proportion of articles of corresponding authors with affiliation in the USA. All data are shown for submitted articles (2003-2020) and accepted articles (1999-2020)

\section{Discussion}

Not surprisingly, most papers published in Biological Invasions have corresponding authors from a small subset of countries in North America, Europe, and Australasia. While multiple factors may contribute to this outcome, these results suggest that this journal does not fully represent invasion science. This situation is not unique to Biological Invasions but also occurs in other ecological sciences (Martin et al. 2012; Nuñez et al. 2019, 2021).

The large number of publications from corresponding authors located in North America, Europe, and Australasia is driven largely by the number of submissions received by Biological Invasions. Through time, the numbers of countries with submissions and acceptances are increasing, but acceptances lag behind submissions (Fig. 2), and the acceptance rate varies substantially among countries. The reasons for the geographic disparity in submissions are manifold, including challenges associated with publishing in English for authors from non-anglophone countries, national population sizes, financial support of ecological research, and interest in and support of scientific publications, among others. While no single journal can solve all these problems, Biological Invasions can take steps to begin to ameliorate some of them, and in fact, some of these efforts are already underway. For example, results of this analysis were shared with the Biological Invasions Editorial Board to make them aware of countries and regions that have published few or no papers in the journal, and editors were encouraged to give this pattern particular consideration. This does not mean that submissions of countries underrepresented in the journal should be accepted more readily, as the scientific rigor employed in assessing the scientific quality of studies should be the same for all submissions.

The number of reviewers from North America was significantly higher than those from other regions (Fig. 3). Reviewer invitations and reviews completed manifested even stronger patterns, with the most invitations by far sent to USA researchers (47\%). This is potentially problematic, since reviewers might lack relevant regional expertise and having uneven geographical representation in the reviewer pool might also affect acceptance rates of different regions. Submissions from the USA have the highest acceptance rates after New Zealand (Table 2), but a deeper dive into the data is necessary to test whether or not the reviewer pool determines which papers are published. Interestingly, the proportion of articles published by researchers based in the USA declined continuously throughout the study period (Fig. 3). Although the proportion remains high, it indicates an increasing diversity of corresponding authors' affiliations. Nonetheless, a more uniform global distribution of reviewers is still an important next step.

Many factors can be driving these geographic disparities. The number of accepted reviewer invitations seems not to vary much among regions (See Fig. 3 and Table 1), suggesting a global interest by researchers in the topic of biological invasions. The disparity in reviewer invitations may simply follow the patterns seen by Kuebbing et al. (2021), where the numbers of editors (and therefore their interaction networks) are heavily weighted towards anglophone nations or those nations where the majority of the population has strong English language skills.

Addressing the issues

Some solutions are beyond the scientific community and this journal, such as allocating budgets to scientific research in a given country or increasing access to English language training. However, we can take 

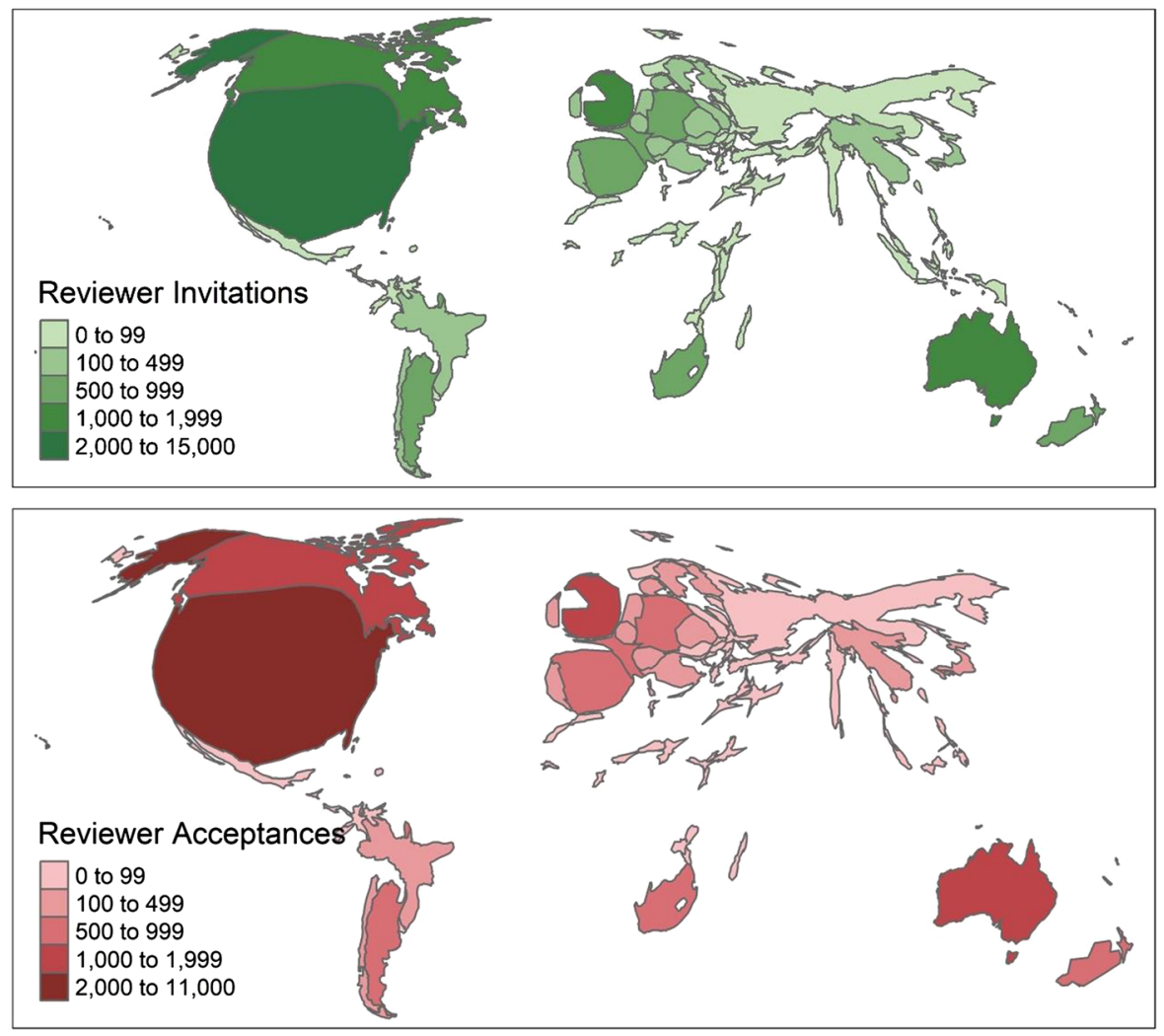

Fig. 3 Cartograms with resized land area based on reviewer invitations (top panel) and accepted reviews (bottom panel) per country to the journal Biological Invasions. Data included all reviewers for Biological Invasions from 2003 to 2020

several steps at Biological Invasions to address some of these disparities. Below we describe the journal's efforts on different fronts including diversifying the editorial board, diversifying reviewers, increasing outreach to unrepresented regions, and continued transparency.

\section{Editorial Board}

At Biological Invasions we have assessed geographic representation on our Editorial Board (Kuebbing et al. 2021) and are taking steps to increase its breadth by identifying and inviting expert researchers from outside of North America and Europe to become Associate Editors. Wider representation on the board may yield different assessments of the novelty and quality of articles submitted to the journal, and it will further diversify our reviewer pool. We believe that maintaining our standards is fundamental and fair for all authors and will in no way preclude increasing diversity. In fact, diversifying the editorial board of Biological Invasions is likely to help us to understand in greater detail what is important or interesting to authors from other regions. We see this benefit as particularly important, because views on what is interesting or important are unlikely to be universal. Recognizing the added burden many international researchers face owing to the requirement of publishing in English, the journal has recently clarified its policies to Associate Editors and reviewers that manuscripts should not be rejected solely based on language issues.

\section{Diversifying reviewers}

The high percentage of reviewers (nearly half) from the United States is troubling. There is, of course, a large community of researchers outside of the United States that is fully capable of reviewing manuscripts for Biological Invasions. While language barriers may exist among some potential reviewers, the dominance of the USA is unwarranted given the number of submissions the journal receives from outside the USA, the large number of other anglophone countries 
globally, and the diversity of our editorial board (see Kuebbing et al. 2021). The journal will take steps to increase reviewer diversity through ongoing discussions at editorial board meetings.

\section{Conclusions}

Not surprisingly, this analysis shows strong geographical disparities. However, we note that our analysis included only corresponding authors and not all authors listed on every submitted and published paper. Therefore, our results present an accurate but incomplete picture. Nonetheless, Springer will publish statistics on the country of affiliation for authors and reviewers in their annual reports for Biological Invasions to track progress and maintain transparency. Other journals focused on invasions, such as Neobiota, Invasive Plant Science and Management, and BioInvasion Records, might consider conducting similar analyses to investigate whether or not similar patterns are observed. We hope our analyses will stimulate discussions in both Biological Invasions and other journals.

Our analysis of the journal Biological Invasions shows the patterns seen in other areas of ecology: a limited set of countries generate most published articles in our pages. This disparity limits our understanding of global phenomena and is likely limiting our understanding of processes and solutions. There is an urgent need for solutions in the field of invasion biology, and we believe that making our science more global will aid this search.

Acknowledgements We thank Springer-Nature for providing us with the data included in this manuscript and in particular Naveen Parthiban for extracting the data and Janet Slobodien and Judith Terpos for their assistance throughout.

Availability of data and materials Data are available from the corresponding author on reasonable request.

\section{References}

Amano T, Sutherland WJ (2013) Four barriers to the global understanding of biodiversity conservation: wealth, language, geographical location and security. Proc R Soc B Biol Sci 280:20122649

Amano T, González-Varo JP, Sutherland WJ (2016) Languages are still a major barrier to global science. PLoS Biol 14:e2000933
Angulo E, Diagne C, Ballesteros-Mejia L, Adamjy T, Ahmed DA, Akulov E et al (2021) Non-English languages enrich scientific knowledge: the example of economic costs of biological invasions. Sci Total Environ 775:144441

Barlow J, França F, Gardner TA, Hicks CC, Lennox GD, Berenguer E et al (2018) The future of hyperdiverse tropical ecosystems. Nature 559:517-526

Chong, K.Y., R.T. Corlett, M. Nuñez, J.H. Chiu, F. Courchamp, W. Dawson, S. Kuebbing, et al. (2021). Are terrestrial biological invasions different in the tropics? Annu Rev Ecol Evol Syst. in press

Hughes KA, Pescott OL, Peyton J, Adriaens T, Cottier-Cook EJ, Key $\mathrm{G}$ et al (2020) Invasive non-native species likely to threaten biodiversity and ecosystems in the Antarctic Peninsula region. Glob Change Biol 26:2702-2716

Jeworutzki S (2016) Cartogram: Create Cartograms with R. R package version 0.0.2. https://CRAN.R-project.org/package= cartogram

Kuebbing SE, McCary MA, Lieurance D, Nuñez MA, Chiuffo MC, Zhang B, Seebens H, Simberloff D, Meyerson LA (2021) A self-study of editorial board diversity at Biological Invasions. Biol Invasions. https://doi.org/10.1007/ s10530-021-02664-8 (this issue)

Lowry E, Rollinson EJ, Laybourn AJ, Scott TE, Aiello-Lammens ME, Gray SM et al (2013) Biological invasions: a field synopsis, systematic review, and database of the literature. Ecol Evol 3:182-196

Maas B, Pakeman RJ, Godet L, Smith L, Devictor V, Primack R (2021) Women and Global South strikingly underrepresented among top-publishing ecologists. Conserv Lett 14:e12797

Mammides C, Goodale UM, Corlett RT, Chen J, Bawa KS, Hariya $\mathrm{H}$ et al (2016) Increasing geographic diversity in the international conservation literature: a stalled process? Biol Conserv 198:78-83

Manlove KR, Belou RM (2018) Authors and editors assort on gender and geography in high-rank ecological publications. PLoS ONE 13:e0192481

Martin LJ, Blossey B, Ellis E (2012) Mapping where ecologists work: biases in the global distribution of terrestrial ecological observations. Front Ecol Environ 10:195-201

Nagendra H (2018) The global south is rich in sustainability lessons that students deserve to hear. Nature 557:485-488

Nuñez MA, Barlow J, Cadotte M, Lucas K, Newton E, Pettorelli $\mathrm{N}$ et al (2019) Assessing the uneven global distribution of readership, submissions and publications in applied ecology: obvious problems without obvious solutions. J Appl Ecol 56:4-9

Nuñez MA, Chiuffo MC, Pauchard A, Zenni RD (2021) Making ecology really global. Trends Ecol Evol 36:766-769

Nuñez MA, Pauchard A (2010) Biological invasions in developing and developed countries: does one model fit all? Biol Invasions 12:707-714

UNESCO Institute for Statistics. (2018). UNESCO Inst. Stat.

Publisher's Note Springer Nature remains neutral with regard to jurisdictional claims in published maps and institutional affiliations. 